\title{
Analysis of the suitability of the German soil texture classification for the regional scale application of physical based hydrological model
}

\author{
H. Bormann \\ University of Oldenburg, Department of Biology and Environmental Sciences, Germany \\ Received: 15 January 2007 - Revised: 27 March 2007 - Accepted: 4 May 2007 - Published: 16 May 2007
}

\begin{abstract}
Regional scale hydrological simulations are mostly based on the use of standard data sets such as soil maps which are based on soil texture classification schemes. This paper analyses the suitability of the German soil texture classification for the application of a physically based soil-vegetation-atmosphere-transfer scheme. Theoretical soil columns are defined to be able to represent the entire soil texture triangle by a $1 \%$ grid of the three particle size classes: sand, clay and silt. These theoretical soil columns are characterized by a homogenous soil texture and consist of two layers of increasing bulk density and decreasing content of organic matter with depth. Soil hydraulic parameterisation is derived by applying a pedotransfer function. Continuous water balance calculations are carried out for a ten year period for all grid cells of the $1 \%$ grid. The results of the water balance calculations are compared to the simulation results of the centre of gravity of the respective soil texture class. Texture class specific mean deviations and root mean squared deviations are calculated from the differences between the $1 \%$ pixels and texture class representatives. The results reveal that the loam and silt texture classes show only small deviations from the centres of gravity. For a few sand texture classes and most of the clay texture classes deviations are considerably large. Assuming an equal distributed probability of occurrence of all realisations within a soil texture class, an uncertainty of more than $100 \mathrm{~mm} / \mathrm{a}$ with respect to runoff and actual evapotranspiration is detected for four clay texture classes, two sand texture classes and one silt texture class. These results are confirmed by a sensitivity analysis investigating the model response for a grid cell compared to the neighboured grid cells. High sensitivities mainly appear for sandy and clayey soils while the sensitivity of the model for loam and silt soils is smaller. Resuming it can be stated that most of the texture classes of the German texture classifi-
\end{abstract}

Correspondence to: H. Bormann

(helge.bormann@uni-oldenburg.de) cation scheme are suitable for the application of a physically based model, on regional scale in particular. Clay texture classes can be expected to cause high simulation uncertainties.

\section{Introduction}

The application of physically based soil-vegetationatmosphere-transfer schemes (SVAT) at the regional scale is mostly based on standard data sets such as regional scale soil maps as detailed measurements of soil hydraulic characteristics are not available. Unfortunately the soil maps mostly do not contain model parameters directly. Information on soil texture, soil compaction and organic content is available only. Thus model parameters have to be taken from literature (e.g. Müller, 1997) or they have to be derived from the readily available data from the soil maps. This can be accomplished by the application of pedotransfer functions (PTF). PTF describe the correlation between soil composition and soil hydraulic parameters. Many of them are based on regression equations of measured soil samples (e.g. Rawls and Brakensiek, 1985). The use of PTF in hydrological modelling is well accepted if no detailed data are available. Several comparative studies have been performed to evaluate different pedotransfer functions (e.g. Wagner et al., 2004; Wösten et al., 2001; Pachepsky and Rawls, 1999; Tietje and Tapkenhinrichs, 1993). However, most PTF continuously describe the relation between soil texture and soil hydraulic parameterisation while soil maps mostly contain the information on soil texture classes only. Thus besides the problem of decreasing information with increasing scale of the soil map (Bormann et al., 1999b) the question on the relevance of uncertainty induced by using classified soil data instead of detailed and continuous soil textural information arises.

Published by Copernicus Publications on behalf of the European Geosciences Union. 


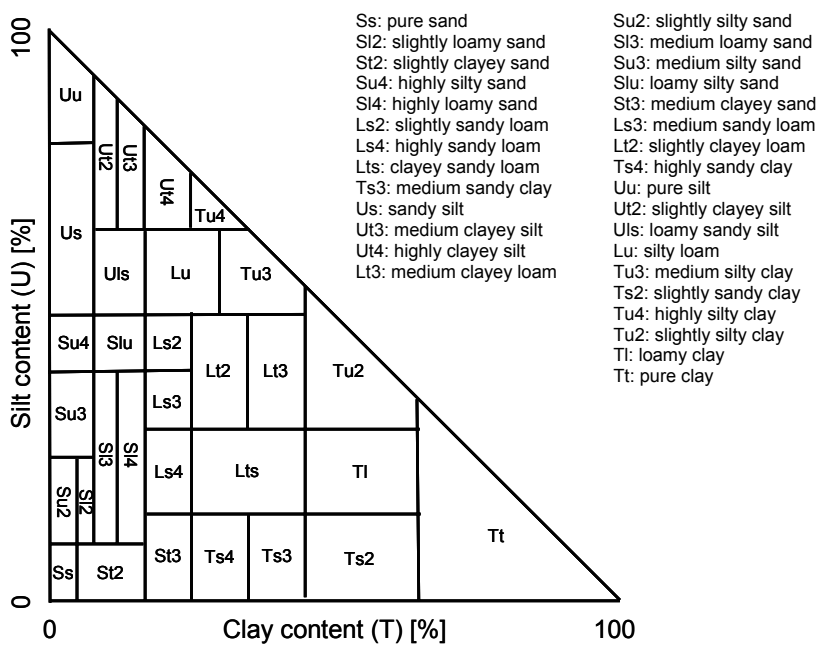

Fig. 1. Definition of the German soil texture classes according to Ad-hoc-AG Boden (2005). $\mathrm{T}=$ clay, $\mathrm{S}=$ sand, $\mathrm{U}=$ silt, $\mathrm{L}=$ loam; 2 = slight, $3=$ medium, $4=$ high .

Based on this problem this study aims at the quantification of the uncertainties of water balance calculations based on soil texture classes. Ensuing, an evaluation of the existing German soil texture classification (Ad-hoc-AG Boden, 2005) for regional scale water balance modelling using a physically based model is carried out. In this study, the soil texture triangle is represented by a $1 \%$ grid of soil texture composition resulting in 5050 different soil textures. As real homogenous soil profiles are not available for all 5050 realisations of the $1 \%$ grid, theoretical soil columns are defined consisting of two layers of homogenous soil texture. So the entire soil texture triangle can be parameterised using a pedotransfer function. Water balance calculations can be performed for the entire space of the soil texture triangle. Based on these calculations, the suitability of any soil texture classification can be analysed by investigating the variability of the model sensitivity on changes in soil texture and by comparing all realisations of a soil texture class with one representative. In this study the centre of gravity (CG) is assumed to be representative for a texture class.

\section{Material and methods}

\subsection{The German soil texture classification}

According to the German soil texture classification (Ad-hocAG Boden, 2005) the soil texture triangle is divided into 31 texture classes: seven clay classes, ten loam classes, seven silt classes and seven sand classes. The boundaries of the texture classes are shown in Fig. 1. For each texture class values on porosity depending on soil compaction are provided. Additionally, correction factors for high organic contents are available.
Table 1. Properties and design of the theoretical soil columns.

\begin{tabular}{cccc}
\hline Layer & Depth & Bulk density & Organic carbon \\
\hline Upper & $0-30 \mathrm{~cm}$ & Low/Medium & $1-2 \%$ \\
Lower & $30-200 \mathrm{~cm}$ & Medium/High & 0
\end{tabular}

\subsection{Simulation model}

The SIMULAT model (Diekkrüger and Arning, 1995; Bormann, 2001) is used in this study to calculate water flows and water balances for all representations of the $1 \%$ grid of the soil texture triangle. SIMULAT is a physically based and one dimensional SVAT scheme using the following process descriptions:

- Potential evapotranspiration is calculated by the Penman-Monteith method. In order to compute the actual evapotranspiration, potential evapotranspiration is reduced by a function taking the actual soil moisture status into account.

- Infiltration is determined using a semi-analytical solution of the Richards' equation according to Smith and Parlange (1978).

- Soil water flow is calculated by a numerical solution of the Richards' equation using finite differences.

- The calculation of the snow melt is based on the degree day method.

- Interflow is computed by Darcy's law. Lateral outflow from a computational layer occurs under partially saturated conditions on an inclined site. The outflow rate is proportional to the saturated lateral conductivity and the inclination.

SIMULAT has been validated by several studies at the plot scale (Diekkrüger and Arning, 1995), at the small catchment scale (Bormann et al., 2005) and at the mesoscale (Bormann et al., 1999a). For small scale applications, the simulation quality without any parameter calibration was comparable to the quality of other calibrated site models (Diekkrüger et al., 1995).

\subsection{Parameter estimation of theoretical soil columns}

As introduced before, no real world data base is available to represent the whole space of the texture triangle in a $1 \%$ grid. Therefore it is decided to introduce theoretical soil columns consisting of a homogenous soil textural composition. To represent an upper humous layer and to approximate the increasing bulk density with depth, two layers are introduced: an upper layer of $30 \mathrm{~cm}$ and a lower layer of $170 \mathrm{~cm}$ depth while the upper layer shows a lower bulk density and a higher 
content of organic carbon compared to the lower layer (Table 1). Porosity is taken from Ad-ho-AG Boden (2005). As porosity values are only available for texture classes, the values provided for different bulk density classes are assumed for the centres of gravity of each texture class. The interpolation between the centres of gravity is performed by a bi-linear approach (Nieschulz, 1997) to provide continuous information on porosity. Finally the pedotransfer function (PTF) of Rawls and Brakensiek (1985) is applied to all theoretical soil columns representing the 5050 pixels of the $1 \%$ grid to derive the soil hydraulic model parameters according to the Brooks and Corey parameterisation for the water retention curve and for the unsaturated conductivity curve. The PTF is applied for the whole space of the texture triangle bearing in mind that Rawls and Brakensiek (1985) limited the applicability to soils with a sand content between $5 \%$ and $70 \%$ and a clay content between $5 \%$ and $60 \%$. The lower boundary condition is defined by free drainage. The theoretical soil columns have an inclination of $15 \%$. They are covered by short grass. A ten year climatic data set (1980-1989) with hourly data of the Göttingen climate station in central Germany is used as model input.

\subsection{Evaluation measures}

In order to evaluate the suitability of the German soil texture classification for the application of the SIMULAT model, three different measures are defined. Applying these measures, the ability of the classification to represent the variability within the texture triangle with respect to the impact of soil texture on the calculation of hydrological fluxes can be estimated. The measures can also be used to evaluate the variability within particular soil texture classes and the ability of class representatives to represent the average behaviour of a texture class.

1. Mean deviation (MD): The mean deviation is defined as the average difference between simulated water flows $(Q)$ of the centre of gravity (CG) of a particular texture class and all $n$ grid cells of the $1 \%$ grid within the texture class. A small MD stands for small deviations in the texture class or for the fact that positive and negative deviations of different grid cells are balanced:

$$
\mathrm{MD}=\frac{\sum_{i=1}^{n}\left(Q_{\mathrm{CG}}-Q_{i}\right)}{n}
$$

2. Root mean squared deviation (RMSD): The RMSD is defined as the root of the average of the squared differences between simulated water flows $(Q)$ of the centre of gravity (CG) of a particular texture class and all $n$ grid cells of the $1 \%$ grid within the texture class. Positive and negative deviations of different grid cells can- not be balanced. Therefore a small RMSD stands for small deviations over the entire texture class:

$\mathrm{RMSD}=\sqrt{\frac{\sum_{i=1}^{n}\left(Q_{\mathrm{CG}}-Q_{i}\right)^{2}}{n}}$

3. Neighbourhood sensitivity (NS): The calculation of the neighbourhood sensitivity of a grid cell is performed by calculating the square root of the mean squared difference between simulated water flows of the grid cell $(i)$ compared to four adjacent grid cells consisting of 1 percent more or less clay $(T)$ and silt $(U)$. Areas with high neighbourhood sensitivity highlight areas where small deviations in the soil composition result in a high modelling uncertainty. Areas of high neighbourhood sensitivity therefore should be represented by small texture classes:

$\mathrm{NS}=$

$\sqrt{\frac{\sum\left(Q_{i}-Q_{U+1 ; T+1}\right)^{2}+\left(Q_{i}-Q_{U+1 ; T-1}\right)^{2}+\left(Q_{i}-Q_{U-1 ; T+1}\right)^{2}+\left(Q_{i}-Q_{U-1 ; T-1}\right)^{2}}{4}}$

From all $n$ neighbourhood sensitivity values within a texture class $\left(\mathrm{NS}_{i}\right)$ the average neighbourhood sensitivity (ANS) is calculated. The average neighbourhood sensitivity therefore is a measure for to assess the uncertainty of the individual texture class with respect to simulated water flows:

$$
\mathrm{ANS}=\frac{\sum_{i=1}^{n} \mathrm{NS}_{i}}{n}
$$

\section{Water balance simulations}

\subsection{Continuous simulations on the soil texture triangle}

Water balance calculations are performed for each of the 5050 theoretical soil columns of the $1 \%$ grid covering the soil texture triangle as well as for the centres of gravity of each soil texture class for a ten year period using model configuration introduced in Sect. 2.3. The first two years of the simulation time are used as warm up period. The results for the remaining eight years are used for the analysis. Figure 2 shows the simulated mean annual water flows for the entire soil texture triangle. As expected from process understanding, sandy and silty soils show highest groundwater recharge rates, while clayey soils have the highest surface runoff generation rates. Actual evapotranspiration is highest for loamy and silty soils while interflow only occurs at clayey and loamy soils. For further analysis the three simulated runoff components (surface runoff, interflow and groundwater recharge) are summed up to the total runoff (QT). Further analyses are performed for OT and for actual evapotranspiration (ET). 

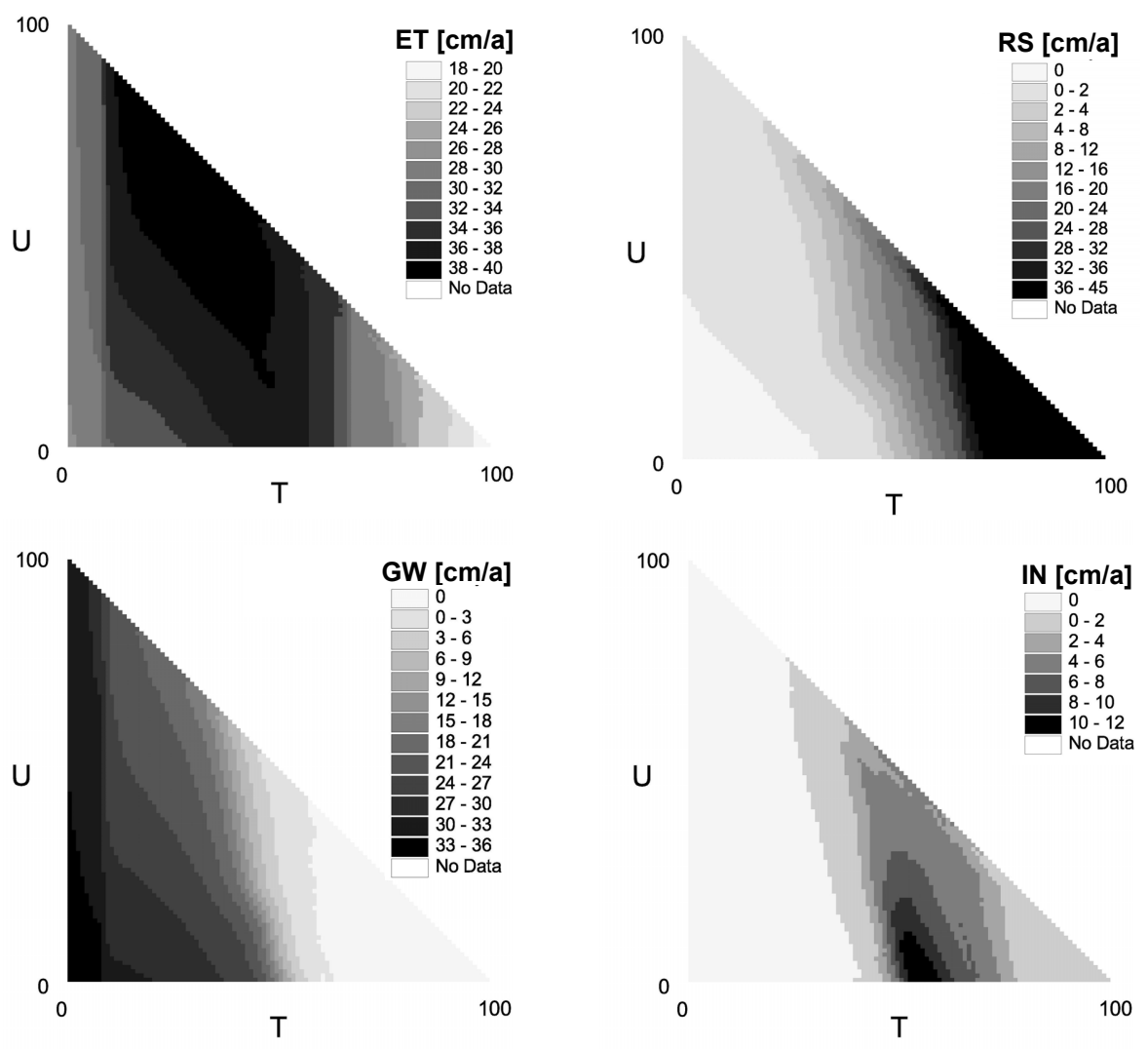

Fig. 2. Simulated annual water flows for a $1 \%$ grid over the soil texture triangle. $\mathrm{ET}=$ actual evapotranspiration, $\mathrm{RS}=$ surface runoff, GW $=$ groundwater recharge, $\mathrm{IN}=$ interflow.

\subsection{Texture class based evaluation of simulation results}

Based on the simulations of the water fluxes based on the $1 \%$ grid and for the centres of gravity of the 31 texture classes according to the Ad-hoc-AG Boden (2005), mean deviations (MD) and root mean squared deviations (RMSD) of the simulated total runoff and actual evapotranspiration are calculated for all texture classes using Eqs. (1) and (2). One should keep in mind that the PTF has not been developed for the entire soil texture triangle. All results are summarised in Table 2. High texture class specific values for MD as well as RMSD can be identified for most of the clay texture classes. Pure clay, loamy clay as well as slightly sandy and slightly silty clay exhibit the highest deviations. High deviations are also detected for loamy sands and for clayey silts, while most loam and silt texture classes show small deviations. Calculating the mean RMSD values for the four main soil textures, clay soils show highest RMSD values $(17.4 \mathrm{~cm} / \mathrm{a}$ for QT and $10 \mathrm{~cm} / \mathrm{a}$ for ET) followed by sandy soils $(6.4 \mathrm{~cm} / \mathrm{a}$ for QT and $5.8 \mathrm{~cm} / \mathrm{a}$ for ET) and loam soils $(5.9 \mathrm{~cm} / \mathrm{a}$ for QT and $6.1 \mathrm{~cm} / \mathrm{a}$ for ET). Silty soils show the smallest RMSD $(5.6 \mathrm{~cm} / \mathrm{a}$ for QT and $6.2 \mathrm{~cm} / \mathrm{a}$ for ET).

An analysis of the structure of the deviations between the grid based water balance calculations and the centres of grav- ity of the texture classes ( $\Delta \mathrm{QT}$, Fig. 3) provides indication for the suitability of the texture classes for regional scale hydrological modelling. It can be assumed that on the regional scale a texture class is represented by a large number of realisations which are equally distributed in the space of the texture class. Deviations therefore compensate with respect to the regional water balance despite soil texture heterogeneity. It is assumed that for regional application a small MD stands for a small uncertainty even if the RMSD is high. On the other hand, texture classes with high MD (and a high RMSD) are assumed to cause a high modelling uncertainty and therefore are less suitable for physically based model applications. In this case, deviations do not compensate but add up with respect to the regional water balance. The modelling uncertainty is higher. For example, the silty loam $(\mathrm{Lu})$ shows low values for both, MD and RMSD. The implied uncertainty is low. The highly loamy sand (S14) has a small MD but a considerably high RMSD. The S14 shows a symmetrical pattern of positive and negative deviations in QT and therefore can also be assumed to cause only small uncertainty on the regional scale. Texture classes causing a high uncertainty even for regional scale model applications for example are the slightly sandy clay (Ts2) and the slightly silty clay (Tu2). Both soils show high MD and RMSD values and ex- 
Table 2. Texture class averages of model sensitivity and texture class internal variability with respect to the simulated total runoff (QT $=$ surface runoff + interflow + groundwater recharge) and the actual evapotranspiration (ET) of the centre of gravity. ANS $=$ average neighbourhood sensitivity; $\mathrm{MD}=$ mean deviation; $\mathrm{RMSD}=$ root mean squared deviation).

\begin{tabular}{|c|c|c|c|c|c|c|c|}
\hline \multirow[t]{2}{*}{ Soil texture } & \multirow[t]{2}{*}{ Soil texture class } & \multicolumn{2}{|c|}{ ANS [cm/a] } & \multicolumn{2}{|c|}{$\mathrm{MD}[\mathrm{cm} / \mathrm{a}]$} & \multicolumn{2}{|c|}{$\operatorname{RMSD}[\mathrm{cm} / \mathrm{a}]$} \\
\hline & & QT & ET & QT & ET & QT & ET \\
\hline \multirow[t]{7}{*}{ Sand } & Pure sand & 1.6 & 1.7 & 1.0 & -1.0 & 3.3 & 3.3 \\
\hline & Slightly silty sand & 1.8 & 1.9 & 1.4 & -1.4 & 3.8 & 3.8 \\
\hline & Slightly loamy sand & 4.1 & 4.2 & 2.3 & -1.9 & 2.6 & 2.2 \\
\hline & Medium loamy sand & 6.9 & 6.8 & 5.4 & -5.4 & 11.6 & 10.3 \\
\hline & Slightly clayey sand & 3.2 & 3.2 & 10.8 & -11.0 & 13.3 & 13.3 \\
\hline & Medium silty sand & 3.1 & 3.2 & 1.1 & -1.2 & 5.0 & 5.3 \\
\hline & Highly silty sand & 3.3 & 3.4 & 1.2 & -1.3 & 5.3 & 5.6 \\
\hline \multirow[t]{10}{*}{ Loam } & Loamy silty sand & 4.5 & 4.5 & 5.2 & -5.1 & 8.5 & 8.5 \\
\hline & Highly loamy sand & 1.1 & 1.1 & 0.2 & -0.6 & 9.0 & 7.5 \\
\hline & Medium clayey sand & 1.3 & 1.2 & -0.2 & 0.1 & 5.1 & 4.9 \\
\hline & Slightly sandy loam & 1.0 & 0.9 & 0.2 & -0.2 & 2.9 & 2.8 \\
\hline & Medium sandy loam & 1.1 & 1.0 & 0.0 & 0.2 & 3.5 & 3.1 \\
\hline & Highly sandy loam & 1.2 & 1.1 & 0.8 & -0.9 & 4.9 & 4.3 \\
\hline & Slightly clayey loam & 0.9 & 0.9 & 1.4 & -1.2 & 5.0 & 4.3 \\
\hline & Clayey sandy loam & 1.0 & 0.9 & 0.8 & -0.5 & 6.2 & 5.9 \\
\hline & Highly sandy clay & 1.5 & 1.4 & 0.6 & -0.7 & 5.9 & 5.6 \\
\hline & Medium sandy clay & 1.2 & 1.1 & 1.8 & -1.7 & 5.2 & 4.6 \\
\hline \multirow[t]{7}{*}{ Silt } & Pure silt & 3.6 & 3.6 & 1.5 & -1.6 & 6.8 & 6.7 \\
\hline & Sandy silt & 3.6 & 3.6 & 1.8 & -1.7 & 6.2 & 6.1 \\
\hline & Slightly clayey silt & 10.0 & 10.0 & 8.4 & -8.2 & 12.4 & 12.5 \\
\hline & Medium clayey silt & 1.6 & 1.7 & 0.2 & -0.3 & 3.0 & 3.1 \\
\hline & Loamy sandy silt & 4.8 & 4.9 & 5.9 & -5.9 & 9.5 & 9.8 \\
\hline & Highly clayey silt & 0.6 & 0.7 & 0.4 & -0.2 & 1.6 & 1.7 \\
\hline & Silty loam & 0.6 & 0.7 & 0.9 & -0.8 & 2.0 & 3.0 \\
\hline \multirow[t]{7}{*}{ Clay } & Medium clayey loam & 0.8 & 0.6 & -0.9 & 0.2 & 3.8 & 3.4 \\
\hline & Medium silty clay & 1.7 & 0.9 & 5.5 & -3.8 & 6.0 & 3.8 \\
\hline & Highly silty clay & 0.5 & 0.5 & -0.6 & 0.5 & 0.9 & 0.9 \\
\hline & Slightly sandy clay & 3.2 & 1.9 & 8.3 & -4.4 & 15.1 & 11.4 \\
\hline & Loamy clay & 5.4 & 1.9 & 14.7 & -2.5 & 28.5 & 13.0 \\
\hline & Slightly silty clay & 9.0 & 2.1 & 26.8 & -4.0 & 37.1 & 10.5 \\
\hline & Pure clay & 8.5 & 4.3 & -16.3 & -4.0 & 30.4 & 27.0 \\
\hline
\end{tabular}

tremely asymmetrical patterns of positive and negative deviations $(\Delta \mathrm{QT})$. Thus, a combination of the results shown in Table 2 and Fig. 3 can be used to classify the texture classes in terms of suitability for physically based modelling in general (small MD and RMSD, symmetric structure of deviations), suitability for regional scale model applications (small MD, large RMSD, symmetric structure of deviations) and limited suitability for model application in general (large MD and RMSD, asymmetric structure of deviations).

\subsection{Analysis of model sensitivity}

The simulations of the water fluxes based on the $1 \%$ grid are also used for the assessment of model sensitivity to $1 \%$ changes in the soil texture composition using Eqs. (3) (neighbourhood sensitivity, NS) and (4) (average neighbourhood sensitivity, ANS). Again it should be kept in mind that er- rors may occur if the PTF is applied for the entire soil texture triangle. Figure 4 shows the neighbourhood sensitivity (NS) for the entire texture triangle, and the texture class specific values of the average neighbourhood sensitivity (ANS) are shown in Table 2. Notably high values of NS are observed for high clay contents (pure clay $(\mathrm{Tt})$ in particular) and for clay contents of $10-14 \%$. For these clay contents the neighbourhood sensitivity is extremely high (independent of the remaining soil composition of silt and sand, Fig. 4). This fact can also be found in Table 2. Besides those texture classes with high clay contents (pure clay (Tt), slightly silty clay (Tu2)) comparably high neighbourhood sensitivities can be found for low clay contents (slightly clayey silt (Ut2), medium loamy sand (S13)). While the texture classes with high clay contents are partly out of the area where the PTF is valid according to Rawls and Brakensiek (1985), the texture classes with 10-14\% clay content mostly are within 


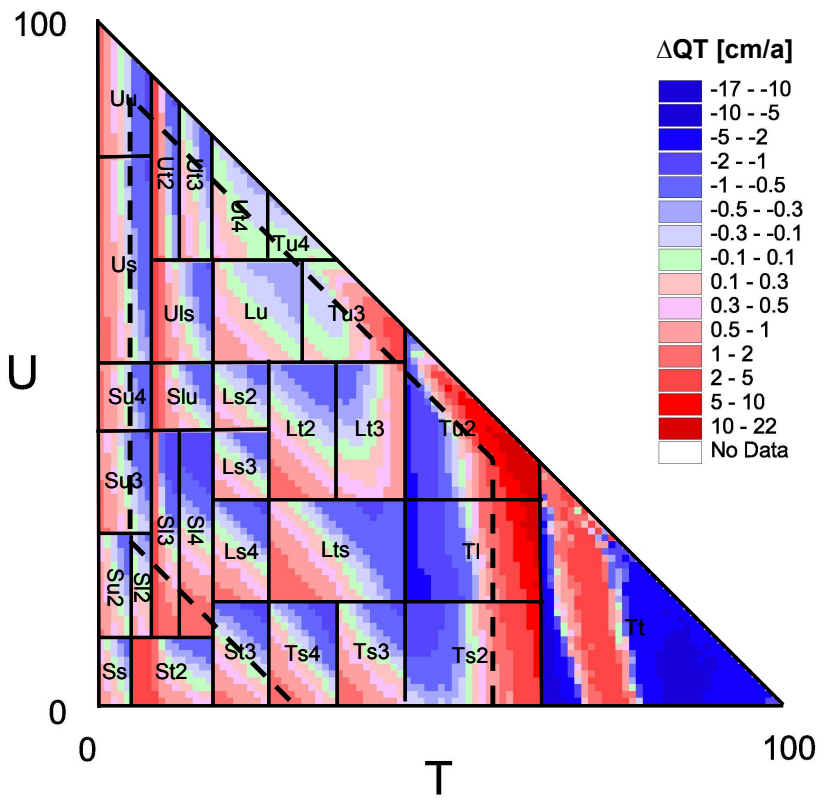

Fig. 3. Deviations between simulated total runoff for the texture class representatives (centres of gravity) compared to all other representations ( $1 \%$ grid points) within a soil texture class $(\Delta \mathrm{QT})$. The central area of the soil texture triangle delimited by the dashed line is the area where the PFT after Rawls and Brakensiek (1985) is valid.

the valid space. But as the sand and silt dominated texture classes are small compared to the clay dominated texture classes (Fig. 1), the identified mean and root mean squared deviations and therefore the uncertainties for model applications are also small compared to those of the clay texture classes. Hence, the analysis of the neighbourhood sensitivity highlights "hot spots" of high model uncertainty and be can used to analyse whether texture classes are small enough to reduce uncertainty to an acceptable level.

\section{Discussion}

The analysis of the simulation results reveals soil texture class specific deviations and sensitivities implying soil texture class specific uncertainties for regional scale model applications. Further model simulations show that the texture class specific systematics of the simulation results does not depend on the definition of the theoretical soil columns and on the chosen boundary conditions of the simulations. Additional simulations with different vegetation cover (mixed forest instead of short grass) result in the same ranking of texture classes with respect to deviations (MD and RMSD). A reduced soil compaction resulting in smaller bulk densities as well as the comparison of dry and wet years have an impact on the size of the deviations but also do not alter the

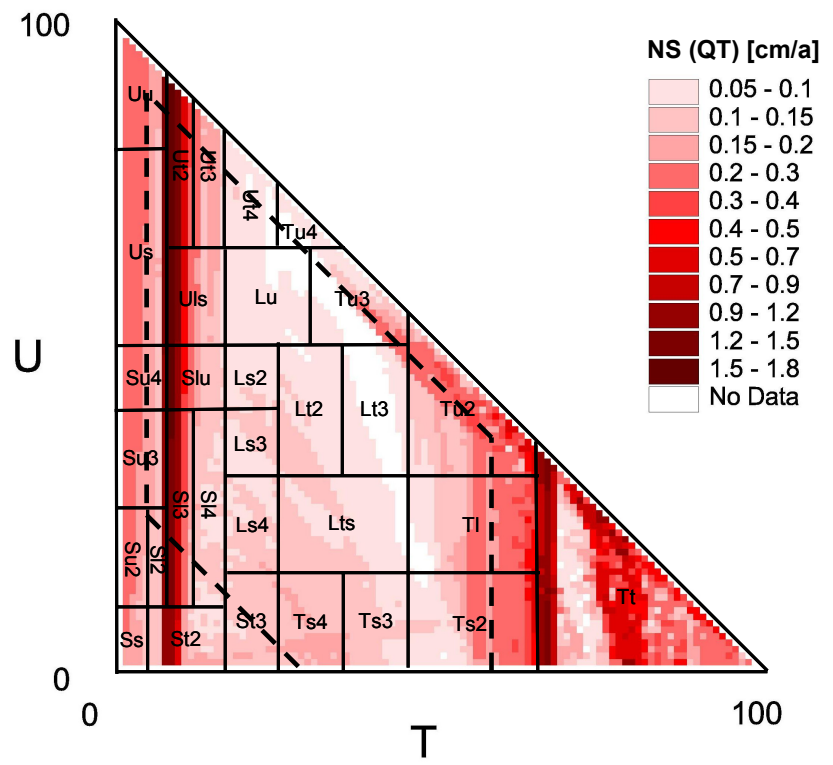

Fig. 4. Neighbourhood sensitivity (NS) for total simulated runoff $(\mathrm{QT}=$ surface runoff + interflow + groundwater recharge $)$. The central area of the soil texture triangle delimited by the dashed line is the area where the PTF after Rawls and Brakensiek (1985) is valid.

ranking of soil texture classes with respect to the deviations as shown by Table 2 .

For all simulation variants the largest uncertainty is detected for clay texture classes. The highest sensitivities besides high clay contents are detected for clay contents between 10 and $14 \%$. This indicates that areas within the texture triangle showing high neighbourhood sensitivities (NS) should be covered by smaller texture classes than areas with low NS values. The German texture classification (Ad-hocAg Boden, 2005) allows for this fact and mostly shows small texture classes for soil textures with 10-14\% clay content (e.g. S13, Ut2, see Fig. 4). Anyway, the clay dominated texture classes cover large areas of the texture triangle and therefore show large deviations (MD and RSMD). So they are expected to cause high uncertainties in the model application. On the other hand soils with clay contents exceeding $60 \%$ are relatively scarce in the field compared to sand and silt dominated soils. Thus the impact on regional scale modelling results may be relatively small. Furthermore as mentioned above the results for soil columns with high clay contents should be handled carefully because the PFT according to Rawls and Brakensiek (1985) may be not valid for those texture classes. The results presented in this study also may be dependent on the chosen representation of the pF-curve (Brook and Corey approach), the PTF and the model code. Therefore additional investigations should be performed, e.g. based on the van Genuchten approach, further PTFs and another SVAT model.

Resuming, the implications of applying the German soil texture classification for regional hydrological modelling can 
be summarized as follows: Silt and loam texture classes show small deviations and sensitivity and therefore are applicable for large scale modelling. Some sand texture classes show large RMSD values and sensitivities, but the classes are small compared to other classes and are therefore applicable for large scale modelling (e.g. S13, Ut2). Clay classes show large deviations and sensitivities (e.g. Tl, Tu2, Ts2). The classes are large compared to other classes and are therefore only applicable for large scale modelling if high uncertainties are acceptable (e.g. in case of small areal fractions of clay soils). With an increasing scale of the soil map also the applicability of classification schemes decreases as the heterogeneity of soil properties can be represented no more. Alternatively, Monte Carlo techniques can be applied to represent the potential variability within soil texture classes instead of one representative (e.g. centre of gravity). This is not necessary in large regions consisting of a large number of simulation units as the high number of units statistically can represent the natural heterogeneity of soils.

\section{Conclusions}

In this study continuous water balance simulations on a $1 \%$ grid covering the entire soil texture triangle have been performed. The results indicate that the highest uncertainties can be expected for clay soils which are partly not covered by the PTF data base. Additionally high sensitivities could be identified for soils with $10-14 \%$ clay content. The German texture classification accounts for this high neighbourhood sensitivity and defines relatively small texture classes except for clay soils. Nonetheless, clay soils with clay contents larger than $60 \%$ show high deviations compared to soil texture class representatives. Therefore high uncertainties can be expected for local and regional scale model applications. While on the local scale observed soil data should be used to minimise uncertainties of model applications, the German texture classification seems to be appropriate for regional scale hydrological model applications because for most soil texture classes, negative and positive deviations in calculated water flows from the class representative are balanced. Only in clay dominated regions the uncertainties caused by soil texture classification may become significant.

Acknowledgements. The author thanks the organisers of the Potsdam-Workshop on "Großskalige Modellierung in der Hydrologie" for the excellent organisation of the Workshop.

Edited by: K.-E. Lindenschmidt

Reviewed by: M. Fink and C. Gattke

\section{References}

Ad-hoc-AG Boden: Bodenkundliche Kartieranleitung, 5. Aufl., 438 p., Hannover, Schweizerbart, 2005.

Bormann, H., Giertz, S., and Diekkrüger, B.: Hydrological catchment models between process representation, data availability and applicability for water management - case study for Benin, IAHS-Publication 295, 86-93, 2005.

Bormann, H.: Hochskalieren von prozessorientierten Wassertransportmodellen - Methoden und Grenzen, München, Herbert-UtzVerlag-Wissenschaft (Reihe Geowissenschaften), 164 p., 2001.

Bormann, H., Diekkrüger, B., and Renschler, C.: Regionalization concept for hydrological modelling on different scales using a physically based model: results and evaluation, Phys. Chem. Earth B., 24(7), 799-804, 1999a.

Bormann, H., Diekkrüger, B., and Richter, O.: Effects of spatial data resolution on the calculation of regional water balances, in: Regionalization in Hydrology, edited by: Diekkrüger, B., Kirkby, M., and Schröder, U., IAHS-Publication, 254, 193-202, 1999b.

Diekkrüger, B. and Arning, M.: Simulation of water fluxes using different methods for estimating soil parameters, Ecol. Model., 81(1-3), 83-95, 1995.

Diekkrüger, B., Söndgerath, D., Kersebaum, K. C., and McVoy, C. W.: Validity of agroecosystem models - A comparison of results of different models applied to the same data set, Ecol. Model., 81(1-3), 3-29, 1995.

Müller, U.: Auswertungsmethoden im Bodenschutz. Dokumentation zur Methodenbank des Niedersächsischen Bodeninformationssystems (NIBIS), Hannover, NLfB, Schweizerbart, 1997.

Nieschulz, K.-P.: Mathematisch-bodenkundliche Regionalisierung des Bodenwasserhaushalts, Landschaftsökologie und Umweltforschung 27, TU Braunschweig, 227 p., 1997.

Pachepsky, Y. A. and Rawls, W. J.: Accuracy and Reliability of pedotransfer Functions as Affected by Grouping Soils, Soil Sci. Soc. Am. J. 63, 1748-1757, 1999.

Rawls, W. J. and Brakensiek, D. L.: Prediction of soil water properties for hydrologic modeling, in: Watershed Management in the Eighties (Proceedings), edited by: Jones, E. and Ward, T. J., ASCE, Denver, Colorado, 30.4.-2.5.1985, 293-299, 1985.

Smith, R. E. and Parlange, J.-Y.: A parameter-efficient hydrologic infiltration model, Water Resour. Res., 14(3), 533-538, 1978.

Tietje, O. and Tapkenhinrichs, M.: Evaluation of pedotransfer functions, Soil Sci. Soc. Am. J., 57, 1088-1095, 1993.

Wagner, B., Tarnawski, V. R., and Stöckl, M.: Evaluation of pedotransfer functions predicting hydraulic properties of soils and deeper sediments, J. Plant Nutr. Soil Sci., 167(2), 236-245, 2004.

Wösten, J. H. M., Pachepsky, Y. A., and Rawls, W. J.: Pedotransfer functions: bridging the gap between available basic soil data and missing soil hydraulic characteristics, J. Hydrol., 251, 123-150, 2001. 